\title{
The importance of good blood pressure control in the prevention of stroke recurrence in hypertensive patients
}

\author{
J. H. JOHNSTON \\ M.R.C.P., Major R.A.M.C. \\ D. G. BEEVERS \\ M.R.C.P. \\ F. G. DUNN \\ H. LARKIN \\ M.R.C.P. \\ M.R.C.P. \\ D. M. TITTERINGTON* \\ Ph.D. \\ Glasgow Blood Pressure Unit and *the Department of Statistics, \\ University of Glasgow, Scotland
}

\begin{abstract}
Summary
One hundred and twenty-four patients $(70$ men and 54 women) who were treated for hypertension after a stroke, between 1968 and 1976, were studied. Twentyone (11 men and 10 women) developed a second stroke after a mean period of just over 2 years. The women who had a stroke recurrence had higher initial systolic and diastolic blood pressure (BP) as well as higher achieved BP. The men with recurrence had no significant difference in initial BP but had higher BP on treatment. Patients who achieved BP of $<160 \mathrm{mmHg}$ systolic or $90 \mathrm{mmHg}$ diastolic had a low incidence of recurrent stroke. Good BP control in hypertensive patients prevents stroke recurrence but may be difficult to achieve.
\end{abstract}

\section{Introduction}

Epidemiological (Kannel, et al., 1970) and actuarial (Lew, 1973) studies have shown that arterial hypertension is the most important single predisposing factor for the development of cerebrovascular stroke. It has now been firmly established that lowering the blood pressure of hypertensive subjects greatly reduces the incidence of subsequent strokes (Hamilton, Thompson, Wisniewski, 1964; Veterans, 1967, 1970; Beevers et al., 1973a, 1978) and it would seem logical to assume that antihypertensive therapy given to patients with high BP who had already had a stroke might prevent stroke recurrence. There are 2 reports (Marshall, 1964; Beevers et al., 1973b) that effective antihypertensive therapy does prevent recurrence in stroke survivors but another study (Hypertension Stroke Cooperative Study Group, 1974) did not show any benefit from lowering the BP in terms of stroke recurrence.
The present authors have undertaken an analysis? of a group of treated hypertensive stroke survivors $\stackrel{\mathbb{D}}{3}$ in Glasgow to try to find out how effective BPo control was in preventing stroke recurrence in theg $\mathrm{e}^{-}$ patients.

\section{Patients and methods}

Using the facilities of the Glasgow Blood Pressure Clinic (Members of the Clinic, 1972), the authors studied the records of all patients attending theo hypertension clinics held in the Glasgow Western疋 and Royal Infirmaries and the Renfrew Blood Pressure Clinic between 1968 and 1976. They identified those who had not been on antihyper- tensive therapy before attendance, had an accurate BP reading before treatment was begun, had beenfollowed-up for a minimum of 12 months and about whom reliable information was available thereaftereven if they had defaulted or died. They only incuded patients aged 65 years or less at the time of the firsto clinic attendance: 1155 patients met these criteria 3 and from this group 89 (50 men and 39 women)o were selected for further study because they had sustained a stroke before attending the clinic, 0 another 35 patients ( 20 men and 15 women) who first developed a stroke while attending the clinicos and who had been followed-up afterwards were alson identified and included. This latter group had beenN attending for a mean period of $24 \cdot 8 \pm 17 \cdot 5$ (s.d.) ${ }_{\sigma}^{\omega}$ months (range 13-67) before the occurrence of the stroke. The total number of patients in the study was therefore 124 ( 70 men and 54 women). Thes diagnosis of stroke was made if there was evidence of sustained neurological damage (usually hemi-ō plegia) due to atherothrombotic cerebrovascular 
disease, or due to intracerebral haemorrhage. Patients who had been diagnosed as having transient cerebral ischaemia were not included since it was felt that in a busy out-patient clinic this diagnosis was often subjective and might be inaccurate. Subarachnoid haemorrhage was also excluded from consideration since it was felt that this condition has a different pathological basis from cerebrovascular stroke. The clinical information was obtained from the notes written by the doctor seeing the patient at the time of the first clinic attendance or by the medical practitioner who treated the patient during the episode.

The goals of therapy in the clinic have always been to reduce the BP levels to as near normal as is safe and practicable. The patients received a full selection of the drugs in use during the period covered in the study. Diuretics, methyldopa, clonidine, $\beta$-blockers, adrenergic blocking agents, reserpine and vasodilators were all used, single or in combination. Twenty-one patients received only one drug (methyldopa or clonidine, 9; thiazide diuretic, 5; $\beta$-blockers, 4; adrenergic ganglion blocking agent, 3). Sixty-one patients were given 2 drugs, the commonest combinations being a diuretic with methyldopa or clonidine (24 patients) and a $\beta$ blocker and diuretic (9 patients). Thirty-eight received 3 drugs and the commonest combinations were thiazide diuretic, methyldopa (or clonidine) with an adrenergic blocking agent (14 patients) and a $\beta$-blocker, thiazide and methyldopa (8 patients). Four patients were given more than 3 drugs.

During follow-up, 21 patients (17\%) 11 men and 10 women, developed a further stroke and in 5 cases $(24 \%)$ this was fatal. The mean period of follow-up before the second stroke was $25 \cdot 8 \pm$ $17 \cdot 2$ months (range, 6-59). The 103 patients who remained free from stroke recurrence were followed up for a mean $38 \cdot 4 \pm 22 \cdot 8$ months (range 3-105).

The 2 groups were compared with respect to age at first attendance (or at the development of the first stroke), initial systolic and diastolic BPs and achieved BPs. The numbers in each group achieving different grades of BP control were also assessed. For those patients presenting after a stroke, the initial BP was taken as the level measured before treatment was started but for those who developed the first stroke after attending the clinic (in view of the fact that they had been on treatment for an average of 2 years) the mean of all clinic BPs (calculated as below), before the stroke occurred, was used. In order to exclude any bias due to difference in frequency of follow-up the achieved BP was calculated by taking the mean readings of every 6-month period then working out the mean of these means for each patient.

Student's $t$ test was used to determine the signifcance of differences between means.

\section{Results}

Table 1 shows the age, initial and achieved BP for male and female patients together. Those who had a recurrence of stroke were noticeably, though not significantly, older. The initial as well as the achieved BP was about $10 \%$ higher.

Table 2 gives the same particulars for men alone. There were no significant differences in age or initial BPs but the achieved pressures were significantly lower in those who did not have a further stroke.

Table 3 gives the values for women. Those who had a recurrence of stroke had markedly higher initial BP as well as higher achieved values.

Again considering both sexes together, 41 patients

TABLE 1. Comparison of BP (in $\mathrm{mmHg}$ ) of hypertensive stroke survivors who remained free from recurrence with those who had another stroke-male and female together (all values ( \pm s.d.))

\begin{tabular}{lccc}
\hline & No recurrence $(n=103)$ & Recurrence $(n=21)$ & Significance \\
\hline Age in years & $52 \cdot 1(7 \cdot 4)$ & $55 \cdot 1(7 \cdot 8)$ & NS \\
Initial systolic BP & $194 \cdot 2(30 \cdot 7)$ & $212 \cdot 6(34 \cdot 6)$ & $P<0.01$ \\
Achieved systolic BP & $167 \cdot 9(23 \cdot 7)$ & $187(25 \cdot 6)$ & $P<0.005$ \\
Initial diastolic BP & $117 \cdot 2(18 \cdot 1)$ & $129(20 \cdot 8)$ & $P<0.005$ \\
Achieved diastolic BP & $102 \cdot 1(12 \cdot 4)$ & $112 \cdot 1(16 \cdot 1)$ & $P<0.005$ \\
\hline
\end{tabular}

TABLE 2. Comparison of BP (in $\mathrm{mmHg}$ ) of male hypertensive stroke survivors who remained free from recurrence with those who had another stroke (all values $( \pm$ s.d.)

\begin{tabular}{lccc}
\hline & No recurrence $(n=59)$ & Recurrence $(n=11)$ & Significance \\
\hline Age in years & $51.6(7 \cdot 7)$ & $54 \cdot 5(9.2)$ & NS \\
Initial systolic BP & $193.9(32 \cdot 2)$ & $201.6(25 \cdot 7)$ & NS \\
Achieved systolic BP & $167 \cdot 1(25)$ & $183.5(19.5)$ & $P<0.025$ \\
Initial diastolic BP & $120(19.2)$ & $121(12.8)$ & NS \\
Achieved diastolic BP & $101.3(11.5)$ & $108.7(11.6)$ & $P<0.05$ \\
\hline
\end{tabular}


TABLE 3. Comparison of BP (in $\mathrm{mmHg}$ ) of female hypertensive stroke survivors who remained free from recurrence with those who had another stroke (all values $( \pm$ s.d.))

\begin{tabular}{lccc}
\hline & No recurrence $(n=44)$ & Recurrence $(n=10)$ & Significance \\
\hline Age in years & $52 \cdot 1(7 \cdot 1)$ & $55.7(6.4)$ & NS \\
Initial systolic BP & $194.6(28.9)$ & $224.6(40 \cdot 3)$ & $P<0.005$ \\
Achieved systolic BP & $168 \cdot 5(22 \cdot 4)$ & $191(31 \cdot 7)$ & $P<0.01$ \\
Initial diastolic BP & $113.5(16)$ & $137.7(24 \cdot 8)$ & $P<0.0005$ \\
Achieved diastolic BP & $103.1(13.6)$ & $115.9(19.9)$ & $P<0.01$ \\
\hline
\end{tabular}

TABLE 4. Hypertensive stroke survivors classified by initial and achieved diastolic blood pressures

\begin{tabular}{clccc}
\hline & \multicolumn{3}{c}{$\begin{array}{c}\text { Blood pressure control } \\
\text { on therapy }\end{array}$} \\
\cline { 3 - 5 } $\begin{array}{c}\text { Initial } \\
\text { BP grading (mmHg) }\end{array}$ & & $\begin{array}{c}\text { Good } \\
(<90 \mathrm{mmHg})\end{array}$ & $\begin{array}{c}\text { Fair } \\
(90-110 \mathrm{mmHg})\end{array}$ & $\begin{array}{c}\text { Poor } \\
(\geqslant 110 \mathrm{mmHg})\end{array}$ \\
\hline Severe & No recurrence & 2 & 14 & 12 \\
$(\geqslant 130)$ & Stroke recurrence & 0 & 3 & 7 \\
Moderate & No recurrence & 2 & 27 & 10 \\
$(110-129)$ & Stroke recurrence & 0 & 4 & 4 \\
Mild & No recurrence & 9 & 26 & 1 \\
$(\leqslant 109)$ & Stroke recurrence & 0 & 3 & 0 \\
\hline
\end{tabular}

achieved a systolic pressure $<160 \mathrm{mmHg}$ and only $2(5 \%)$ had another stroke while 83 had an achieved systolic pressure $\geqslant 160 \mathrm{mmHg}$ of whom 19 $(23 \%)$ had a recurrence $\left(\chi^{2}=6.33, P<0.025\right)$. Forty-five achieved a diastolic BP $<100 \mathrm{mmHg}$ and 3 of these $(7 \%)$ had a recurrence as compared with $18(23 \%)$ of the 79 with an achieved diastolic pressure $\geqslant 100 \mathrm{mmHg}\left(\chi^{2}=5.29, P<0.025\right)$.

Table 4 shows all the patients classified by diastolic BP as having mild, moderate or severe hypertension initially and as achieving good, fair or poor control of BP. No patient with good control had another stroke. Of those achieving fair BP control, $10 \%$ who initially had mild hypertension, $13 \%$ who had moderate hypertension and $18 \%$ who had severe hypertension had another stroke, while of the patients whose BP was poorly controlled, $20 \%$ initially with moderate hypertension and $37 \%$ with severe hypertension had a recurrence.

\section{Discussion}

In studies of elderly stroke survivors in Belfast (Adams, 1965; Merrett and Adams, 1966), no evidence was found that hypertension exerted any adverse effect on prognosis or survival; indeed, those with high BP had a lower mortality over the first 2 months. The patients were in the 'geriatric' age group, however, and those findings are unlikely to apply to younger subjects. Marshall and Kaeser (1961) had shown that a diastolic BP of $>110 \mathrm{mmHg}$ impaired life expectancy in stroke survivors; but they found no influence of BP on the stroke recurrence rate. Marshall (1964) was nevertheless able to demonstrate that the incidence of further cerebrovascular accidents was significantly lower in 18 men who received antihypertensive treatment thar in 25 controls, although no significant differences was found between treated and untreated female stroke survivors.

Carter (1970) also carried out a prospectof controlled trial of hypotensive therapy in 97 stroke survivors and found that if treatment was effect in reducing BP, prognosis was improved in patients under 65 years (but was worsened if the treatmens was not effective). Stroke recurrence rates wereo lessened in the treated patients but the numbers? were too small for statistical analysis.

Beevers et al. (1973b) studied 162 treated hyper $\overrightarrow{\hat{O}}$ tensive survivors of 'cerebrovascular disease' which included transient cerebral ischaemia, subarachnoide haemorrhage and mental change as well as paralytie stroke. The recurrence rate was found to be closelyo related to the adequacy of control of the hyper 3 . tension. The Hypertension-Stroke Cooperative Study? Group (1974) in America carried out a prospective study of 452 hypertensive patients who had suffereक a stroke but showed no benefit in respect of stroke recurrence from antihypertensive therapy as? opposed to placebo tablets (although there was as lower incidence of cardiac failure in the treated. patients). Most of the patients were black and they were in the main mildly hypertensive (mean BP $167 / 100 \mathrm{mmHg}$ ) which may explain the dis crepancy between this and most of the other studiesw (including this one) which were carried out on more severely hypertensive, white patients.

The present figures show that BP control wasD particularly poor in patients who had a recurrent? stroke. The women who had a recurrence had more severe hypertension initially than those who did nof 
have another stroke but in the men the adequacy of BP control was the only significant difference between the 2 groups. Even in the patients who did not have a recurrence, BP control was not very good and 23 of them $(22 \%)$ were poorly controlled.

Indeed, it has recently been shown that good BP control is only achieved in a minority of all patients attending the Glasgow Blood Pressure Clinic (Johnston et al., 1980) and similar findings have been reported from other hospital clinics both in the United Kingdom (Beevers et al., 1973a; Beilin et al., 1980) and in the United States (Alderman and Ochs, 1977).

There are several possible explanations for suboptimal control. It may be that some patients by reason of their disability were unable to remember to take their tablets regularly or that side effects made effective treatment intolerable. It is possible, though, that in some cases the BP was deliberately kept higher than normal for fear of causing further brain damage by reducing cerebral perfusion. In the present patients, however, the risk of stroke recurrence seemed to be small if the systolic BP was kept below $160 \mathrm{mmHg}$ and the diastolic below $100 \mathrm{mmHg}$ and the authors suggest that in patients aged 65 years or less who have had a stroke, the therapeutic aim should be to reduce the BP to nearnormal limits taking the due precautions to avoid too sudden a drop in pressure, since too rapid a reduction of BP has been shown by Ledingham and Rajagopalan (1979) to be a cause of cerebral infarction in patients with accelerated hypertension.

\section{References}

AdAMs, G.F. (1965) Prospects for patients with strokes with special reference to the hypertensive hemiplegic. British Medical Journal, 2, 253.

Alderman, M.H. \& OCHS, O.S. (1977) Treatment of hypertension at the University Medical Clinic. Archives of Internal Medicine, 137, 1707.

Beevers, D.G., Fairman, M.J., Hamilton, M. \& Harpur, J.E. (1973a) The influence of antihypertensive treatment over the incidence of cerebral vascular disease. Postgraduate Medical Journal, 49, 905.

Beevers, D.G., Fairman, M.J., Hamilton, M. \& Harpur, J.E. (1973b) Antihypertensive treatment and the course of established cerebral vascular disease. Lancet, i, 1407.
Beevers, D.G., Johnston, J., Devine, B.L., Dunn, F.G., LARKIN, H. \& TITTERINGTON, D.M. (1978) Relation between prognosis and blood pressure before and during treatment of hypertensive patients. Clinical Science and Molecular Medicine, 55, 333S.

Beilin, L.J., Bulpitt, C.J., Coles, E.C., Dollery, C.T., GeAR, J.S.S., HARPER, G., JoHNSON, B.F., MUNROFAURE, A.D. \& TuRner, S.C. (1980) Long-term antihypertensive drug treatment and blood pressure control in three hospital hypertension clinics. British Heart Journal, 43, 74.

Carter, A.Barham (1970) Hypotensive therapy in stroke survivors. Lancet, i, 485.

Hamilton, M., Thompson, E.W. \& Wisniewski, T.K.M. (1964) The role of blood pressure control in preventing complications of hypertension. Lancet, i, 235.

HyPERTENSION-STROKe CoOperative STUDY Group (1974) Effect of antihypertensive treatment on stroke recurrence. Journal of the American Medical Association, 229, 409.

JoHNSTON, J.H., LORIMER, A.R., RODGER, J.C., ROBERTSON, W.K., Thomas, A., LAWrence, W. \& Fife, R. (1980) Control of hypertension in out-patients. Experience of the Glasgow Blood Pressure Clinic. Postgraduate Medical Journal, 56, 633.

Kannel, W.B., Wolf, P.A., Verter, J. \& McNamara, P.M. (1970) Epidemiological assessment of the role of blood pressure in stroke. The Framingham Study. Journal of the American Medical Association, 214, 301.

Ledingham, J.G. \& RaJagopalan, C. (1979) Cerebral complications in the treatment of accelerated hypertension. Quarterly Journal of Medicine, 48, 25.

LEW, E.A. (1973) High blood pressure, other risk factors and longevity: the insurance viewpoint. American Journal of Medicine, 55, 281.

MARShALL, J. (1964) A trial of long-term hypotensive therapy in cerebrovascular disease. Lancet, $\mathbf{i}, 10$.

Marshall, J. \& Kaeser, A.C. (1961) Survival after nonhaemorrhagic cerebrovascular accidents. A prospective study. British Medical Journal, 2, 73.

Members of THE Clinic (1972) The Glasgow Blood Pressure Clinic. Journal of the Royal College of Physicians of London, 7, 87.

MerReTt, J.D. \& Adams, G.F. (1966) Comparison of mortality rates in elderly hypertensive and normotensive hemiplegic patients. British Medical Journal, 2, 802.

Veterans Administration CoOperative Study Group on ANTIHYPERTENSIVE AGENTS (1967) Effects of treatment on morbidity in hypertension. Results in patients with diastolic blood pressures averaging 115 through 129 mm Hg. Journal of the American Medical Association, 202, 116.

Veterans Administration Cooperative Study Group on ANTIHYPERTENSIVE AGENTS (1970) Effects of treatment on morbidity in hypertension II. Results in patients with diastolic blood pressures averaging 90 through $114 \mathrm{~mm} \mathrm{Hg}$. Journal of the American Medical Association, 213, 1143. 